\title{
Social Equality in the Number of Choice Options Is Represented in the Ventromedial Prefrontal Cortex
}

\author{
Ryuta Aoki, ${ }^{1,2}$ Madoka Matsumoto, ${ }^{1}$ Yukihito Yomogida, ${ }^{1,2}$ Keise Izuma, ${ }^{2,3}$ Kou Murayama, ${ }^{2,4}$ Ayaka Sugiura, ${ }^{5}$ \\ Colin F. Camerer, ${ }^{3}$ Ralph Adolphs, ${ }^{3}$ and Kenji Matsumoto ${ }^{1}$ \\ ${ }_{1}^{1}$ Tamagawa University Brain Science Institute, 6-1-1, Tamagawa-gakuen, Machida, Tokyo 194-8610, Japan, ${ }^{2} J a p a n$ Society for the Promotion of Science, \\ 5-3-1, Koji-machi, Chiyoda-ku, Tokyo 102-8471, Japan, ${ }^{3}$ Division of the Humanities and Social Sciences, California Institute of Technology, Pasadena, \\ California 91125, ${ }^{4}$ Department of Psychology, University of California Los Angeles, Los Angeles, California 90095, and ${ }^{5}$ Department of Cognitive and \\ Behavioral Science, University of Tokyo, 3-8-1, Komaba, Meguro-ku, Tokyo 153-8902, Japan
}

A distinct aspect of the sense of fairness in humans is that we care not only about equality in material rewards but also about equality in nonmaterial values. One such value is the opportunity to choose freely among many options, often regarded as a fundamental right to economic freedom. In modern developed societies, equal opportunities in work, living, and lifestyle are enforced by antidiscrimination laws. Despite the widespread endorsement of equal opportunity, no studies have explored how people assign value to it. We used functional magnetic resonance imaging to identify the neural substrates for subjective valuation of equality in choice opportunity. Participants performed a two-person choice task in which the number of choices available was varied across trials independently of choice outcomes. By using this procedure, we manipulated the degree of equality in choice opportunity between players and dissociated it from the value of reward outcomes and their equality. We found that activation in the ventromedial prefrontal cortex (vmPFC) tracked the degree to which the number of options between the two players was equal. In contrast, activation in the ventral striatum tracked the number of options available to participants themselves but not the equality between players. Our results demonstrate that the vmPFC, a key brain region previously implicated in the processing of social values, is also involved in valuation of equality in choice opportunity between individuals. These findings may provide valuable insight into the human ability to value equal opportunity, a characteristic long emphasized in politics, economics, and philosophy.

Key words: neuroeconomics; reward system; social comparison

\section{Introduction}

Opportunities to choose freely, whether over health care, marriage partners, or political representatives, are considered a fundamental human right in most developed and democratic societies (Inglehart et al., 2008; Delhey, 2009; Welzel and Inglehart, 2010). However, inequality in opportunity to choose is also a pervasive feature of many societies and cultures. Historical examples include slavery, voting restrictions, political participation, civil rights, marriage, apartheid, and segregation. Struggles to equalize freedom to choose can span decades and require extraordinary efforts by historical figures, such as Martin Luther

Received 0ct. 9, 2013; revised March 15, 2014; accepted April 2, 2014

Author contributions: R. Aoki, M.M., Y.Y., K.I., K. Murayama, A.S., C.F.C., R. Adolphs, and K. Matsumoto designed research; R. Aoki, M.M., Y.Y., A.S., and K. Matsumoto performed research; M.M. contributed unpublished reagents/ analytic tools; R. Aoki analyzed data; R. Aoki, Y.Y., K.I., K. Murayama, C.F.C., R. Adolphs, and K. Matsumoto wrote the paper.

This work was supported by a Grant-in-Aid for the Japan Society for the Promotion of Science Fellows to R. Aoki (no. 249856), Grand-in-Aid for Scientific Research on Innovative areas to K.Matsumoto (no. 24120717), and a Tamagawa University Global Center of Excellence grant from the Ministry of Education, Culture, Sports, Science, and Technology, Japan. We thank Dr Adam Phillips for assistance.

The authors declare no competing financial interests.

Correspondence should be addressed to Kenji Matsumoto, Tamagawa University Brain Science Institute, 6-1-1, Tamagawa-gakuen, Machida, Tokyo 194-8610, Japan. E-mail: matsumot@lab.tamagawa.ac.jp.

DOI:10.1523/JNEUROSCI.4427-13.2014

Copyright $\odot 2014$ the authors $\quad 0270-6474 / 14 / 346413-09 \$ 15.00 / 0$
King, Nelson Mandela, and Aung San Suu Kyi (Kennedy, 1989; Silverstein, 1996; Brookfield, 2008). Modern examples exist, such as societal debates over same-sex marriage and women's rights to choose in many countries. These examples also remind us that equality in opportunity is not universally accepted for all choices, by all people and societies.

There is an important distinction between equality in opportunity and equality in outcome, which are different dimensions of social equality (Arneson, 1989; Roemer, 2002; Breen, 2010). Humans are unique in having developed social systems that value equality in opportunity (Béteille, 1986, 1994; Flemming et al., 2006). Modern developed societies seem to generally more clearly and universally value equality in opportunity than equality in outcomes (Marshall et al., 1999; Breen, 2010). Of course, equal opportunities do not ensure equal outcomes. However, inequality in outcomes is tolerated, and even celebrated, if it results from fair competition based on equal opportunity (Marshall et al., 1999).

Despite these examples of the apparent societal importance of equality in opportunity, previous studies have exclusively focused on neural underpinnings of equality in outcomes (Sanfey et al., 2003; Tabibnia et al., 2008; Tricomi et al., 2010; Baumgartner et al., 2011). Our study is the first to investigate the neural basis of people's subjective valuation of equality in opportunity to 
A

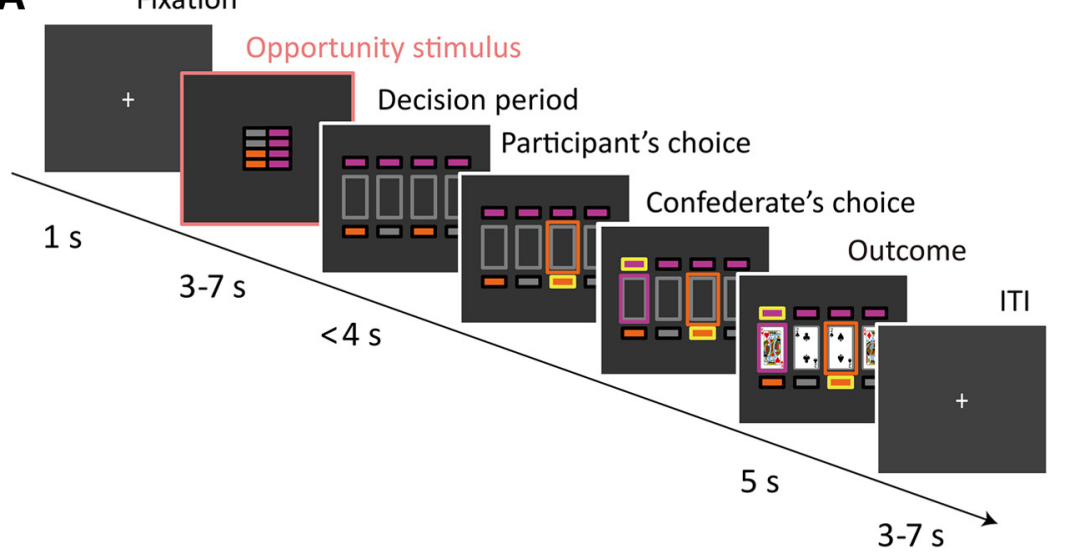

B

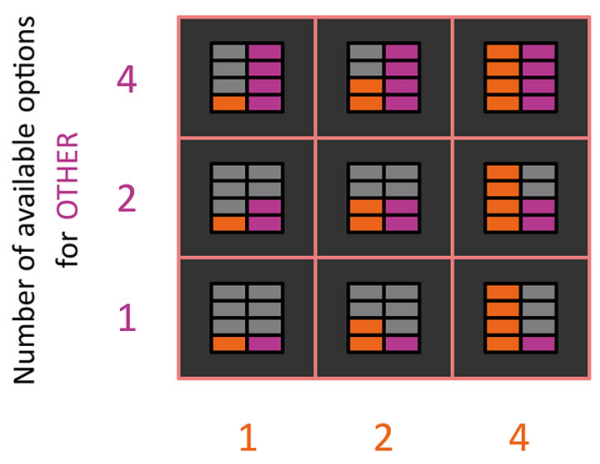

Number of available options for SELF

C

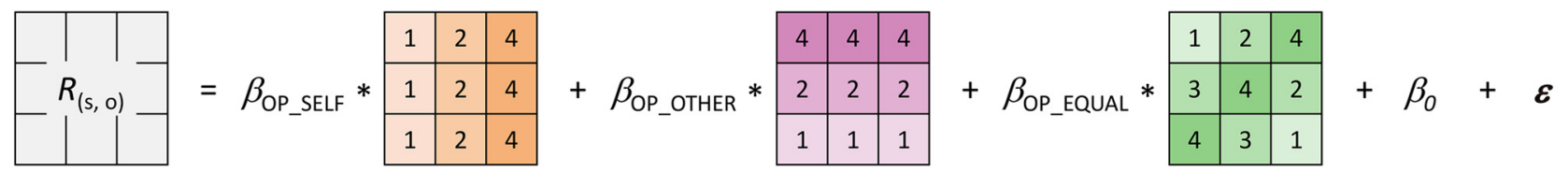

Figure 1. Two-person choice task. A, A trial started with the presentation of an "opportunity stimulus" that indicated the number of choice options available to a participant (SELF) and confederate (OTHER). During the subsequent decision period, each player chose one of the options available to them (the confederate's choice was actually determined by computer). The reward outcomes of their choices were indicated by cards (a face card was associated with monetary rewards whereas a deuce was associated with no reward). In the example shown in the figure, there are two options available to the participant, and four to the confederate. Upon choice, the participant's chosen option is highlighted, followed by the revealed choice of the confederate, followed by simultaneous showing of both of their outcomes ("no reward" for the participant and "reward" for the confederate in this case). B, Opportunity-stimulus conditions. The numbers of choice options for SELF and OTHER were manipulated independently. $C$, The regression model used to analyze the neural responses to the opportunity stimuli. The $3 \times 3$ matrices represent the nine opportunitystimulus conditions shown in $\boldsymbol{B}$. The same model was also used to analyze subjective emotional pleasantness (Fig. $2 B)$. The $\beta$ coefficients indicate how the dependent variables $\left(R_{(s, 0)}\right.$ : the neural responses or subjective emotional pleasantness) of an individual are sensitive to (1) the number of available options for the participant $\left(\beta_{0 \mathrm{OP} \text { SELF }}\right)$, (2) those for the confederate $\left(\beta_{0 \mathrm{P} \_ \text {OTHER }}\right)$, and (3) the "choice equality" or the degree of equality in the numbers of available options between the two players ( $\left.\beta_{\text {OP_EQuAL }}\right)$, quantified using the absolute value of their difference.

choose, using functional magnetic resonance imaging (fMRI). To disentangle the effect of equality in opportunity from that of equality in outcome, we developed a novel task derived from the economic theories that characterize the value of opportunity of choice based on the sheer number of options available, regardless of the value of outcome (Pattanaik and Xu, 1990; Kranich, 1996). In this "two-person choice task" (Fig. 1A), the numbers of options available to a participant ("SELF") and a confederate ("OTHER") were individually manipulated on a trial-by-trial basis, which yielded equal and unequal social situations in terms of their opportunities to choose. Of note, the probability of obtaining a reward outcome was fixed regardless of the numbers of options available. We focused on the neural activity in the ventral striatum (VS) and ventromedial prefrontal cortex (vmPFC), which are known to be involved in value processing (Fliessbach et al., 2007; Behrens et al., 2009; Kringelbach and Berridge, 2009; Mobbs et al., 2009; Haber and Knutson, 2010; Clithero et al., 2011; Bartra et al., 2013). We predicted that these regions would be responsive to the value represented by the number of options, even though it was not associated with monetary value in and of itself.

\section{Materials and Methods}

Participants. Twenty-three undergraduates participated in the study after providing written informed consent. Two females did not complete the experiment due to time constraints. One male completed the experiment but was excluded from the analysis because of excessive head motion $(>2$ $\mathrm{mm}$ ) during the main task. The remaining 20 participants ( 8 females, 12 males; mean age, 20.8 years; range, $19-23$; $\mathrm{SD}=1.28$ ) were included in the analysis. All participants had normal or corrected-to-normal vision and had no history of psychiatric illness or neurological disease. The study was approved by the ethical committee of Tamagawa University.
Two-person choice task. Participants were instructed to perform a twoperson choice task with another person, who was actually a confederate and his/her choices were determined by the computer. The task was designed to dissociate the numbers of options for players from the probability of obtaining a reward outcome. A trial (Fig. 1A) started with the presentation of an "opportunity stimulus," which signaled the numbers of options available to a participant (SELF) and a confederate (OTHER). The colors indicating the option numbers for SELF and OTHER were counterbalanced across participants. After a 3-7 s randomized interval, positions of options available to the players were displayed, and participants had to choose one of the available options within $4 \mathrm{~s}$. The option chosen by participants was highlighted, and after a short delay $(0.8-1.6 \mathrm{~s})$ the confederate's choice was also displayed. After a $2 \mathrm{~s}$ interval, reward outcomes for SELF and OTHER were displayed for $5 \mathrm{~s}$. Outcomes were either 1000 yen ("reward," indicated by a face card) or 0 yen ("no reward," indicated by a deuce). In all trials, two of the four cards were face cards, so that the probability of a reward outcome was $50 \%$ regardless of the number of options available. The intertrial interval (ITI) was randomized from 3 to $7 \mathrm{~s}$.

There were 1,2, or 4 available options for SELF and OTHER, independently manipulated on a trial-by-trial basis, resulting in nine $(3 \times 3)$ conditions for the opportunity stimulus (Fig. 1B). The degree of equality in opportunity to choose (hereafter referred to as "choice equality") was defined on the basis of how small the difference in the numbers of options between the two players was, regardless of the outcomes of their choices (Fig. 1C). For example, the choice equality was defined to be highest when the two players had the same numbers of options available (Arneson, 1989; Kranich, 1996). Each opportunity-stimulus condition was repeated 12 times in the scanner (108 trials in total). The outcomes for SELF and OTHER (either reward or no reward) were determined independent of the opportunity-stimulus conditions, resulting in four $(2 \times 2)$ conditions for the outcome. Unbeknownst to participants, the outcomes for the players were controlled by the computer to balance the actual frequencies of a reward outcome among the nine opportunity- 
A

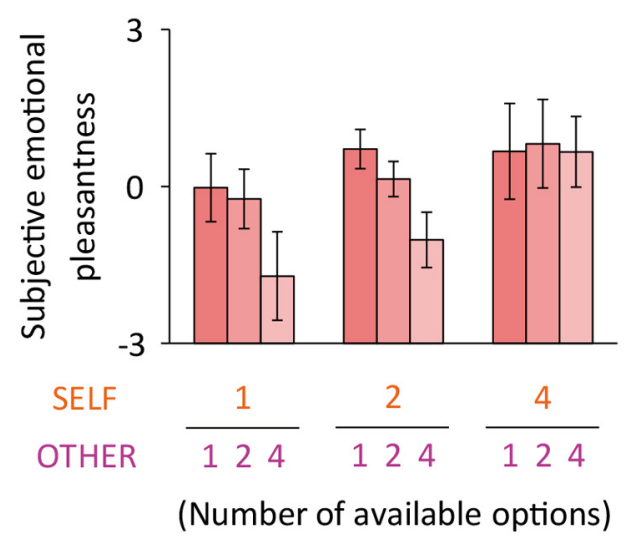

B
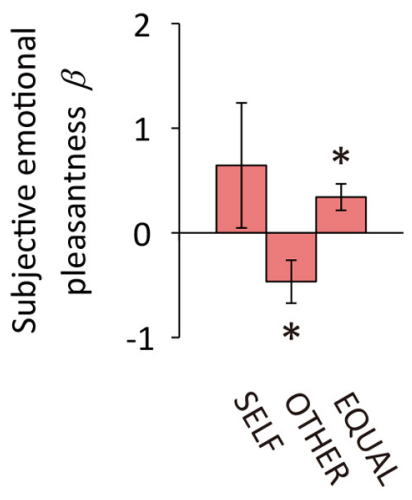

Figure 2. Sensitivity of subjective emotional pleasantness on the numbers of options available. $\boldsymbol{A}$, Self-reported emotional pleasantness of opportunity stimuli. Participants rated the subjective emotional pleasantness of each of the nine combinations of the opportunity stimuli immediately after the scan. $\boldsymbol{B}$, The effects on the subjective emotional pleasantness of the number of options for SELF $\left(\beta_{\text {OP_SELF }}\right)$, that for OTHER $\left(\beta_{\text {OP_OTHER }}\right)$, and the equality in option numbers (i.e., choice equality) between the two players ( $\beta_{O P \text { EQUAL }}$, quantified using the absolute value of the difference between self and other options). Error bars depict SEM; ${ }^{*} p<0.05$ (one-sample $t$ test, two-tailed).

stimulus conditions. This ensured that the number of options had indeed no effect on the expected value of the outcome. Note that this task involved no direct competition between the players. In the decision phase, participants could choose any one of the available options regardless of whether it was also available to the confederate; in the outcome phase, both players could be rewarded individually (rather than sharing a reward) when they had chosen the same option that was revealed to be a reward outcome.

MID task. Participants also performed the monetary incentive delay (MID) task to help us independently localize regions sensitive to monetary reward (Knutson et al., 2001; Kuhl et al., 2010; Zaki et al., 2011). Each trial started with an $800 \mathrm{~ms}$ cue indicating the amount of potential monetary gain or loss (neutral: \pm 0 yen; low gain: +20 yen; high gain: +400 yen; low loss: -10 yen; high loss: -200 yen; 20 trials for each cue), followed by a fixation cross $(2.0-2.5 \mathrm{~s})$. A white square ("target") was then presented for $100-700 \mathrm{~ms}$, and participants had to press a button before the target disappeared. Subsequently, a feedback message indicating whether participants successfully responded or not ("hit" or "miss"; accompanied by the amount of gain/loss in the trial) was presented for $800 \mathrm{~ms}$. In gain trials, participants earned the indicated money for a hit response, but earned no money for a miss response. In loss trials, they avoided losing the indicated money for a hit response but lost the money for a miss response. The ITI was jittered between 2.0 and $4.0 \mathrm{~s}$.

To equate the task performance (hit rates) across participants, we adjusted task difficulty for each participant by adaptively changing the duration of the target presentation: if the participant's hit rate after the $n^{\prime}$ th trial was $>66 \%$, the duration of target presentation (initialized to $250 \mathrm{~ms}$ ) for the next trial was decreased by $25 \mathrm{~ms}$ (minimum: $100 \mathrm{~ms}$ ); if the hit rate after the $n^{\prime}$ th trial was $<66 \%$, the target duration for the next trial was increased by $25 \mathrm{~ms}$ (maximum: $700 \mathrm{~ms}$ ). This procedure ensured that a participant's hit rate was $\sim 66 \%$ (Knutson et al., 2001; Kuhl et al., 2010; Zaki et al., 2011).

Experimental procedure. The experiment consisted of four phases: (1) pretask instruction, (2) fMRI scan for the main task, (3) postscan subjective ratings, and (4) the second fMRI scan for the MID task. Participants were first introduced to a same-sex confederate. Participants and the confederate were recruited from different universities and had never met each other before. Both the participant and confederate received the instructions, but they did not meet again after the participant entered the scanner.

During the instructions, participants were told that the positions of available options and the face cards (associated with reward outcomes) were independently determined at random in each trial so that no effective strategy could be learned. In addition, to avoid forming the incorrect belief that the probability of a reward outcome depended on the number of options, we explicitly told participants that it was always $50 \%$ for both players, regardless of the numbers of available options. Furthermore, to confirm whether they correctly understood the task instructions, participants were asked to fill in the blanks of the following question:

"Given the fact that the number of the face cards is always_out of the 4 cards, the probability that you obtain a reward outcome in a trial is _\%, regardless of the number of options available. Likewise, the probability that the other player obtains a reward outcome is_\%."

All participants answered correctly (2, 50, and 50), indicating that they clearly understood this point before the fMRI scan. In the instruction phase, participants and the confederate were seated face-to-face at a table and performed several practice trials to make participants believe that they were playing the game with another person. Participants were told that the amount of a reward per trial in the practice was set to 500 yen (one-half of that in the actual experiment) and that the players could earn some money depending on the outcomes of three randomly selected trials. In actuality, the outcomes were controlled by the computer and the payoffs for participants and the confederate were always 500 and 1000 yen, respectively. The difference in their payoffs was intended to make participants more sensitive to the existence of the confederate while they performed the main task in the scanner.

After the instruction phase, participants entered the MRI scanner and performed the main task. The task was organized into three $13 \mathrm{~min}$ sessions, each consisting of 36 trials. Participants were told before the scan that the outcomes of three randomly chosen trials (one from each session) would actually be paid to them. Thus, each participant had a chance to earn 0-3000 yen. In fact, the payment for the main task was fixed for all participants ( 1000 yen) so as not to influence the results of the subsequent MID task.

After the scan, participants completed a self-report questionnaire assessing the subjective emotions (happiness, sadness, anger, and disgust) to the opportunity stimuli. The question was "how did you feel (happy, sad, angry, or disgusted) when you saw the opportunity stimuli?" Participants rated their emotions for each of the nine opportunity stimuli using a 7 point scale $(1=$ not at all, $7=$ extremely). The raw ratings were transformed into $Z$-scores for each participant and emotion to normalize individual differences in the use of rating scales (Hare et al., 2010). The resulting scores were aggregated across the scales to produce a composite measure [happiness - (sadness + anger + disgust)], which was used for the analysis of subjective rating data (Fig. 2). The $Z$-scores of the nine opportunity stimuli showed a similar pattern across the four subscales (Pearson correlation coefficients between any two subscales: $|r|$ ranged from 0.52 to 0.86 ; mean $|r|=0.70, p<0.05$ ), which validated the use of the composite measure. We refer to this measure as "subjective emotional pleasantness." Participants were also asked to answer the perceived probability (percentage of all trials) of face-card appearance for each of the four option positions. Their answers were used to analyze the potential influence of perceived variance in option values on the value of the number of options (see Results).

After a short break, participants received an instruction for the MID task, and re-entered the scanner. The MID task was separated into two sessions (50 trials per session). Participants were told that the payment for the MID task was the sum of the outcomes of all trials. The actual payment for the MID task was 4620 yen for all participants.

$f M R I$ data acquisition. Functional imaging was conducted using a 3-tesla Siemens Trio A Tim MRI scanner. Interleaved T2*-weighted gradient-echo echo-planar imaging (EPI) sequences were used to obtain functional images $(42$ slices, $3 \times 3 \mathrm{~mm} \times 3 \mathrm{~mm}$ voxels, field-of-view $=$ 
$192 \mathrm{~mm}^{2}, 64 \times 64$ matrix, slice gap $=0 \mathrm{~mm}$, repetition time $=2500 \mathrm{~ms}$, echo time $=25 \mathrm{~ms}$, flip angle $=90^{\circ}$ ). Slice orientation was tilted $-30^{\circ}$ from the anterior commissural-posterior commissural line to reduce the signal dropout in the vmPFC (Deichmann et al., 2003). A highresolution anatomical T1-weighted image $(1 \times 1 \times 1 \mathrm{~mm})$ was also acquired for each participant.

$f M R I$ data preprocessing. Data were analyzed using Statistical Parametric Mapping (SPM8, Wellcome Department of Imaging Neuroscience, Institute of Neurology, London, UK; http://www.fil.ion.ucl.ac.uk/spm/). The first three volumes of each scanning session were discarded before data processing to allow for stabilization of the magnetization. Images were corrected for slice acquisition time within each volume, motioncorrected with realignment to the first volume, spatially normalized to the standard Montreal Neurological Institute EPI template (resampled to $3 \times 3 \times 3 \mathrm{~mm}$ voxels), and spatially smoothed using a Gaussian kernel with a full-width at half-maximum of $8 \mathrm{~mm}$.

fMRI data analysis. For each participant, the blood-oxygen leveldependent (BOLD) responses were modeled with general linear models (GLMs). Trial-related regressors were convolved with a canonical hemodynamic response function provided by SPM8. For the main task, the GLM included the following parametric regressors: (1) presentation of the opportunity stimulus, modulated by (a) the number of available options for SELF, (b) that for OTHER, and (c) the choice equality (Fig. $1 C)$; and (2) presentation of the reward outcomes, modulated by (a) the outcome for SELF ( reward $=1$, no reward $=0$ ), $(\mathrm{b})$ that for OTHER (reward $=1$, no reward $=0$ ), and (c) the equality in the outcomes between the players (equal outcome $=1$, unequal outcome $=0$ ). This model yielded six $\beta$ values of interest ( $\beta_{\mathrm{OP} \_S E L F}, \beta_{\mathrm{OP} \_ \text {OTHER }}, \beta_{\mathrm{OP} \_ \text {EQUAL }}$ for activation responding to opportunity stimuli; $\beta_{\mathrm{OU}}$ _SELF,$\beta_{\mathrm{OU}}$ _OTHER, $\beta_{\text {OU_EQUAL }}$ for activation responding to reward outcomes). The model also included the following regressors of no interest: the decision period (with duration of reaction time) and presentation of the confederate's choice. The regressor for the decision period and the regressor for presentation of the confederate's choice were parametrically modulated by the number of options for SELF, that for OTHER, and the degree of equality in the option numbers between the players (identical to the regressor for the opportunity stimulus). A regressor for error trials and six motion parameters were also included in the model.

For the MID task, the GLM included the following regressors of interest: (1) presentation of the cue, modulated by potential monetary gain (neutral $=0$, low gain $=1$, high gain $=2)$; (2) presentation of the gain outcome; and (3) presentation of the no-gain outcome. The model also included the following regressors of no interest: presentation of the cues in the loss trials (low-loss and high-loss cues) and presentation of the outcomes in the loss trials (loss and no-loss outcomes). The loss trials were not used for localizing the reward systems in accordance with previous studies (Kuhl et al., 2010). A regressor for error trials and six motion parameters were also included in the model.

Because we had a priori hypothesis focusing on the activations of the reward system (i.e., the VS and vmPFC), the second-level group analysis was performed for the voxels within these regions identified by the independent reward-localizer task (i.e., the MID task). First, we created anatomical masks encompassing the VS and vmPFC, using the Automated Anatomical Labeling atlas of the WFU Pickatlas toolbox for SPM (Tzourio-Mazoyer et al., 2002; Maldjian et al., 2003). The mask for the VS consisted of the bilateral caudate and putamen and bounded caudally at $y=0$ to include only the anterior parts of the striatum (Izuma et al., 2010). The mask for the vmPFC consisted of the bilateral medial orbitofrontal gyrus and gyrus rectus (FitzGerald et al., 2012; Janowski et al., 2013; Murayama et al., 2013). Second, within these anatomical masks, we identified the peak activation voxels responding to monetary rewards during the MID task (determined by a second-level group analysis). For the VS, we selected a voxel showing the maximum effect of potential monetary gains, identified using the parametric regressor for the cue (Kuhl et al., 2010). For the vmPFC, we selected a voxel showing the maximum effect in the contrast of monetary gain versus no-gain outcome (Kuhl et al., 2010). Third, we averaged the neural $\beta$ values ( $\beta_{\text {OP_SELF}}$, $\beta_{\text {OP_other }}, \beta_{\text {OP_EQUAL }}, \beta_{\text {OU_SELF }}, \beta_{\text {OU_otheR }}$, and $\left.\beta_{\text {OU_EQUAL }}\right)$ within a 6-mm-radius sphere surrounding each of these activation peaks, and performed a one-sample $t$ test (vs 0 ). The variables followed a normal distribution ( $p>0.235$, Kolmogorov-Smirnov test). This procedure ensured that the selection of the voxels and subsequent analysis were statistically independent. We also performed an exploratory whole-brain analysis for completeness, with a height threshold of $p<0.05$, corrected for familywise error (FWE) across whole brain.

Brain-behavior correlations. Neural betas ( $\beta_{\mathrm{OP} \_\mathrm{SELF}}, \beta_{\mathrm{OP} \_\mathrm{OTHER}}$, and $\beta_{\mathrm{OP} \_\mathrm{EQUAL}}$ ) for individual participants were averaged within the same 6-mm-radius spheres used in the group-average analysis. Behavioral betas were obtained by submitting the subjective-rating data (the composite measure) to the same three-factor regression model used in the analysis of the neural responses to the opportunity stimuli (Fig. 1C). The variables derived from subjective ratings followed a normal distribution $(p>0.230)$. Relations between the neural $\beta$ and subjective emotional pleasantness $\beta$ were examined using Pearson correlations.

\section{Results}

\section{Subjective emotional pleasantness}

We first examined self-reported emotional ratings for various choice opportunities. Participants rated their subjective emotional pleasantness (see Materials and Methods for details) of each of the nine opportunity stimuli (Fig. 1B) immediately after the scan. Although the probabilities of the reward outcome were the same for all conditions, and participants were explicitly informed of this fact before the scan, the subjective emotional pleasantness of the opportunity stimuli varied significantly across conditions (Fig. 2A). To examine the effects of the numbers of options quantitatively, we analyzed the subjective emotional pleasantness of each participant using a three-factor regression model (Fig. 1C). This model assessed the dependencies of the individual subjective emotional pleasantness on (1) the number of options for SELF, (2) the number of options for OTHER, and (3) the choice equality, or the degree of equality in the numbers of options between SELF and OTHER (Fig. 2B). The regression showed that subjective emotional pleasantness became more positive as the choice equality increased $\left(\beta_{\mathrm{OP} \_\mathrm{EQUAL}}: t_{(19)}=2.69\right.$, $p=0.015$, one-sample $t$ test), and they became more negative as the number of options for OTHER increased $\left(\beta_{\text {OP_OTHER }}: t_{(19)}=\right.$ $-2.27, p=0.035)$. The number of options for SELF had no significant effect ( $\left.\beta_{\text {OP_SELF }}: t_{(19)}=1.08, p=0.294\right)$, possibly due to large interindividual variation (the variance of $\beta_{\mathrm{OP} \text { SELF }}$ differed significantly from that of $\beta_{\mathrm{OP} \text { OTHER }} ; \chi_{(1)}^{2}=24.1, p<$ 0.001 , likelihood-ratio test for equivalence of variances). These results suggest that the subjective emotional pleasantness of choice opportunity is substantially modulated by social comparison of the number of available options. In particular, the choice equality between individuals had a positive effect on subjective emotional pleasantness. It is also notable that the subjective emotional pleasantness $\beta_{\text {OP_SELF }}$ and $\beta_{\text {OP_OTHER }}$ were negatively correlated across participants $(r=-0.55, p=0.012)$, indicating that the more individuals valued their own choice opportunities, the more they tended to devalue the other player's. The subjective emotional pleasantness $\beta_{\text {OP_EQUAL }}$ was not correlated with $\beta_{\text {OP_SELF }}(r=-0.05, p=0.826)$ or with $\beta_{\text {OP_OTHER }}(r=-0.11$, $p=0.655)$.

\section{Neural response to reward outcome}

Before analyzing the neural responses to the opportunity stimuli, we confirmed that the reward-coding voxels identified by the independent reward-localizer task (activation peaks: $x=15, y=$ $11, z=-5$ for the VS; Fig. $3 A ; x=9, y=44, z=-14$ for the vmPFC; Fig. $4 A$ ) also responded to the reward outcome during the two-person choice task. The neural responses to the reward outcomes were analyzed based on a three-factor model that sep- 
A

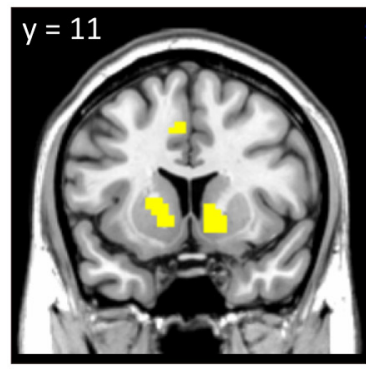

VS $(15,11,-5)$
B

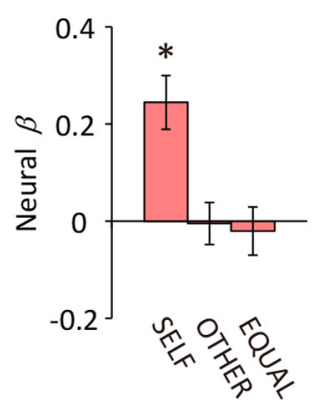

C

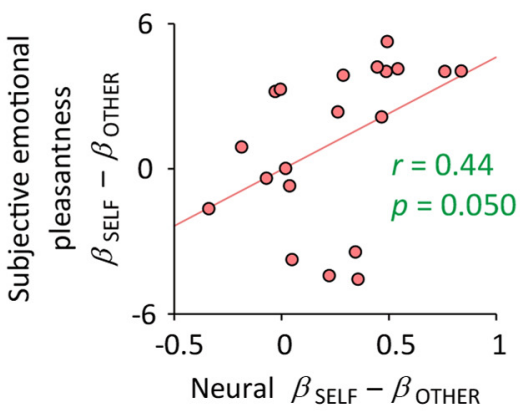

D

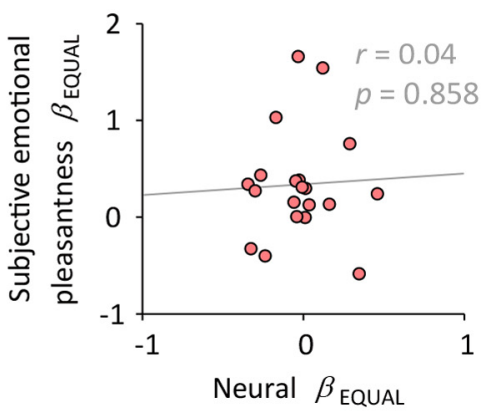

Figure 3. Neural responses in the VS. $\boldsymbol{A}$, The VS as identified by the independent reward-localizer task. The VS was significantly activated ( $p<0.05$, FWE-corrected within the VS anatomical mask) during the MID task in response to potential monetary gains. Image is shown at a stringent threshold ( $p<0.0001$, whole-brain FWE-corrected; $k \geq 10$ ) for display. $\boldsymbol{B}$, Activation in the VS in response to the opportunity stimuli. Neural $\beta$ values were averaged within a $6 \mathrm{~mm}$ radius sphere surrounding the peak voxel determined by the group-level random-effects analysis for the reward-localizer task. Error bars depict SEM; ${ }^{*} p<0.05$ (one-sample $t$ test, two-tailed). $\boldsymbol{C}, \boldsymbol{D}$, Relations between neural responses and subjective emotional pleasantness sensitivities. The neural $\beta$ for the number of options for SELF minus that for OTHER ( $\left.\beta_{\text {OP_SELF }}-\beta_{\text {OP_OTHER }}\right)$ was positively correlated with that derived from the subjective emotional pleasantness across participants $(\boldsymbol{C})$. On the other hand, the neural $\beta$ for choice equality $\left(\beta_{O P \text { EQuaL }}\right)$ was not correlated with that derived from the subjective emotional pleasantness $(\boldsymbol{D})$. Pearson correlation coefficients $(r)$ and associated $p$ values (two-tailed) are shown in the figure.
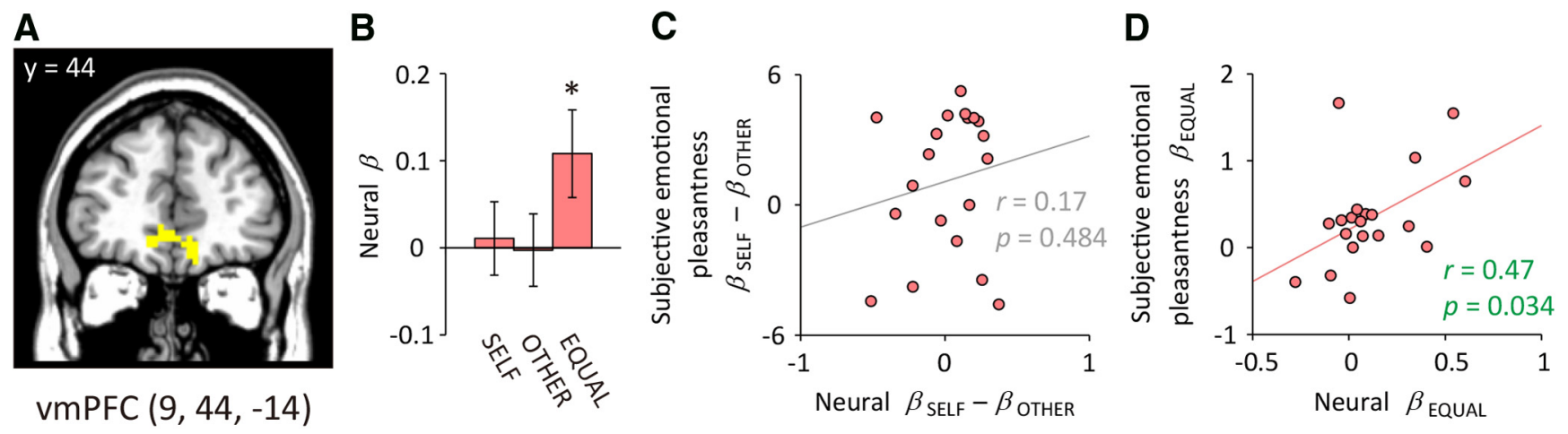

Figure 4. Neural responses in the vmPFC. $\boldsymbol{A}$, The vmPFC as identified by the independent reward-localizer task. The vmPFC was significantly activated ( $p<0.05$, FWE-corrected within the vmPFC anatomical mask) in response to monetary gain versus no-gain outcomes during the MID task. Image is thresholded at $p<0.001$, uncorrected; $k \geq 10$ for display. $\boldsymbol{B}$, Activation in the vmPFC in response to the opportunity stimuli. Neural $\beta$ values were averaged within a 6-mm-radius sphere surrounding the peak voxel determined by group-level random-effects analysis for the reward-localizer task. Error bars depict SEM; ${ }^{*} p<0.05$ (one-sample $t$ test, two-tailed). $\boldsymbol{C}, \boldsymbol{D}$, Relations between neural responses and subjective emotional pleasantness sensitivities. The neural $\beta$ for the number of options for SELF minus that for OTHER ( $\left.\beta_{\text {OP_SELF }}-\beta_{\text {OP_OTHER }}\right)$ was not significantly correlated with that derived from the subjective emotional pleasantness across participants $(\boldsymbol{C})$. On the other hand, the neural $\beta$ for choice equality $\left(\beta_{O P}\right.$ EOUAL $)$ was positively correlated with that derived from subjective emotional pleasantness (D). Pearson correlation coefficients $(r)$ and associated $p$ values (two-tailed) are shown in the figure.

Table 1. Neural responses to reward outcome in the two-person choice task

\begin{tabular}{llrl}
\hline Region & Contrast & \multicolumn{1}{l}{$t$} & $p$ \\
\hline $\operatorname{VS}(15,11,-5)$ & $\beta_{\text {OU_SELF }}>0$ & 3.48 & 0.003 \\
& $\beta_{\text {OU_OTHER }}>0$ & -1.04 & 0.309 \\
& $\beta_{\text {OU_EQUAL }}>0$ & -0.92 & 0.368 \\
$\operatorname{vmPFC}(9,44,-14)$ & $\beta_{\text {OU_SELF }}>0$ & 2.67 & 0.015 \\
& $\beta_{\text {OU_OTHER }}>0$ & -0.58 & 0.567 \\
& $\beta_{\text {OU_EQUAL }}>0$ & 3.27 & 0.004 \\
\hline
\end{tabular}

arated the effects of the outcome for SELF, that for OTHER, and equality in the outcomes between the players (see Materials and Methods). As expected, both the VS and vmPFC were sensitive to the reward outcome for SELF (Table 1), consistent with the large literature describing the role of these regions in processing monetary reward outcomes (Tricomi et al., 2004; Fliessbach et al., 2007; Mobbs et al., 2009; Haber and Knutson, 2010; Kang et al., 2013). Furthermore, the vmPFC showed an increased activation to the equality in the outcomes between the players (Table 1), in line with the results of previous studies reporting vmPFC activations to equitable monetary allocations between self and other
(Tabibnia et al., 2008; Tricomi et al., 2010; Baumgartner et al., 2011; Zaki and Mitchell, 2011).

\section{Neural response to opportunity stimulus}

The neural responses to the opportunity stimuli were analyzed using the same three-factor regression model as was used in the analysis of subjective emotional pleasantness (Fig. 1C). The VS showed significantly greater activation in response to an increasing number of available options for SELF (Fig. $3 B ; \beta_{\mathrm{OP} \text { SELF }}: t_{(19)}$ $=4.43, p<0.001$; one-sample $t$ test). This VS activation was not explained by the expected outcome values because the probability and magnitude of the reward outcome was fixed across conditions. The VS activation was not significantly modulated either by the number of options for OTHER $\left(\beta_{\text {OP_OTHER }}: t_{(19)}=-0.10\right.$, $p=0.918)$ or by the choice equality $\left(\beta_{\mathrm{OP} \_\mathrm{EQUAL}}: t_{(19)}=-0.41\right.$, $p=0.690)$. We further examined whether interindividual variations in VS reactivity to the number of options were associated with variations in self-reported emotional pleasantness. The sensitivity of the VS activation to the number of options for SELF with reference to that for OTHER (i.e., neural $\beta_{\text {OP_SELF }}-$ $\beta_{\text {OP_OTHER }}$ ) was positively correlated with that of the subjective 
Table 2. Significant activations identified by whole-brain analysis for the two-person choice task

\begin{tabular}{|c|c|c|c|c|c|c|}
\hline \multirow[b]{2}{*}{ Contrast } & \multirow[b]{2}{*}{ Brain region (peak activation) } & \multicolumn{3}{|c|}{ MNI coordinates } & \multirow[b]{2}{*}{ PeakZ } & \multirow{2}{*}{$\begin{array}{l}\text { Cluster size } \\
\text { (no. voxels }\end{array}$} \\
\hline & & $x$ & $y$ & $z$ & & \\
\hline \multirow[t]{3}{*}{$\beta_{\mathrm{OP}_{\mathrm{S} S E L F}}>0$} & Occipital cortex (left) & -27 & -73 & 37 & 5.19 & $2\left(2720^{a}\right)$ \\
\hline & Supplementary motor area (right) & 3 & 17 & 52 & 5.13 & $26\left(2720^{a}\right)$ \\
\hline & Dorsomedial prefrontal cortex (left) & -6 & 32 & 37 & 4.82 & $1\left(2720^{a}\right)$ \\
\hline$\beta_{\text {OP_OTHER }}>0$ & - & & & & & \\
\hline$\beta_{O P_{\text {_EQUAL }}}>0$ & - & & & & & \\
\hline \multirow{5}{*}{$\beta_{\text {OU_SELF }}>0$} & Posterior orbitofrontal cortex (right) & 24 & 17 & -20 & 5.10 & $2\left(568^{b}\right)$ \\
\hline & VS (left) & -12 & 5 & -14 & 4.93 & $6\left(568^{b}\right)$ \\
\hline & VS (right) & 9 & 5 & -11 & 4.91 & $3\left(568^{b}\right)$ \\
\hline & Rostral anterior cingulate cortex (left) & -3 & 41 & 7 & 4.89 & $1(549)$ \\
\hline & Central orbitofrontal cortex (left) & -36 & 35 & -11 & 4.84 & $1(375)$ \\
\hline$\beta_{\text {OU_OTHER }}>0$ & - & & & & & \\
\hline
\end{tabular}

Results are based on a second-level random-effects analysis. Activations were identified by a height threshold of $p<0.05$, FWE-corrected across the whole brain. Cluster sizes in the parentheses indicate the numbers of voxels when a height threshold of $p<0.001$, uncorrected, was applied.

${ }^{a}$ These regions belonged to a single cluster.

${ }^{b}$ These regions belonged to a single cluster.

No activation was found in the inversed contrasts.

emotional pleasantness (i.e., subjective emotional pleasantness $\beta_{\text {OP_SELF }}-\beta_{\text {OP_OTHER }}$; derived from the regression analysis of the subjective rating data) across participants (Fig. $3 C$; Pearson correlation coefficient $r=0.44, p=0.050$; after controlling for age and gender, $r=0.44, p=0.069)$. In contrast, the sensitivity of the VS activation to the choice equality (i.e., neural $\beta_{\text {OP_EQUAL }}$ ) was not significantly correlated with that of the subjective emotional pleasantness (i.e., subjective emotional pleasantness $\beta_{\mathrm{OP} \_\mathrm{EQUAL}}$; derived from the regression analysis of the subjective rating data; Fig. $3 D ; r=0.04, p=0.858$ ).

In contrast, the vmPFC activation significantly increased with the choice equality (Fig. $4 B ; \beta_{\mathrm{OP} \text { EQUAL }}: t_{(19)}=2.15, p=0.045$ ), but not with the number of available options for SELF ( $\beta_{\mathrm{OP} \text { SELF }}$ : $\left.t_{(19)}=0.26, p=0.801\right)$ or for OTHER $\left(\beta_{\text {OP_OTHER }}: t_{(19)}=-0.06\right.$, $p=0.950)$. In other words, the vmPFC activation was enhanced when the options available to each of the two players were more equal, regardless of the absolute number of options for each player. Furthermore, the sensitivity of the vmPFC to the choice equality (i.e., neural $\beta_{\text {OP_EQUAL }}$ ) was positively correlated with the sensitivity of the subjective emotional pleasantness (i.e., subjective emotional pleasantness $\beta_{\mathrm{OP} \_\mathrm{EQUAL}}$ ) across participants (Fig. $4 D ; r=0.47, p=0.034$; after controlling for age and gender, $r=0.48, p=0.043)$. The vmPFC response to the number of options for SELF with reference to that for OTHER (i.e., neural $\beta_{\text {OP_SELF }}-\beta_{\text {OP_OTHER }}$ ) was not significantly correlated with the corresponding subjective emotional pleasantness (i.e., subjective emotional pleasantness $\beta_{\text {OP_SELF }}-\beta_{\text {OP_OTHER }}$ ) across participants (Fig. $4 C ; r=0.17, p=0.484$ ).

To examine whether neural activation patterns observed in the VS and vmPFC were statistically different or not, we performed a two-way ANOVA with region (VS or vmPFC) and regressor (SELF or EQUAL) as within-subject factors. We found no significant main effect of the region $\left(F_{(1,19)}=1.74, p=0.203\right)$ or regressor $\left(F_{(1,19)}=2.65, p=0.120\right)$, but we did find a significant interaction between the two factors $\left(F_{(1,19)}=19.9, p<0.001\right)$. This significant region by regressor interaction confirmed a differential activation pattern between the VS and vmPFC. Specifically, the VS is preferentially activated by the number of options for participants themselves, whereas the vmPFC is preferentially activated by the choice equality. To further characterize the regional specificity, we also looked at brain activation in all voxels within the combined anatomical mask of VS and vmPFC. When we applied a statistical threshold equivalent to that used in the localizerbased analysis $(p<0.05$, uncorrected, without an extent threshold; note that this analysis is not for statistical significance testing, but to assess the spatial distributions of activated voxels), we found that all voxels responding to the increased number of options for SELF $(2 \leq$ $y \leq 23$ in the MNI coordinates) belonged to clusters in the bilateral VS, whereas all voxels responding to the increased choice equality ( $26 \leq y \leq 50$ in the MNI coordinates) belonged to clusters in the vmPFC. These results indicated a robust regional specificity without any bias in voxel selection that might have been caused by the localizer task.

An exploratory whole-brain analysis identified significant activation to the number of options for SELF in the several brain areas outside the a priori regions-of-interest (Table 2). The neural responses to the number of options for OTHER and to the choice equality were not significant outside the a priori regions of interest (Table 2).

\section{Does perceived probability of reward outcome explain VS response to the number of options?}

Although the objective probability of a reward outcome was fixed across conditions, there was a concern that a perceived bias in the probability of a reward outcome had influenced the VS activation to the number of options for SELF. However, the results of the following additional analyses suggest that the observed VS activation is not explained by the perceived probability of a reward outcome. First, before scanning, participants actively answered to a question asking the probability of a reward outcome independent of the number of options, confirming that they had explicit knowledge about the objective probability (see Materials and Methods). If participants still had an implicit belief that a larger number of options was associated with a higher probability of a reward outcome, the VS activation to the number of options for SELF (i.e., the neural $\beta_{\text {OP_SELF }}$ ) should be largest in the first session and decrease over the sessions, because participants would learn through the experience that the number of options was not related to the probability of a reward outcome. However, our data indicates that this was not the case: There was no trend in the 
neural $\beta_{\text {OP_SELF }}$ over the three sessions $\left(F_{(2,38)}=0.33, p=0.721\right.$, one-way repeated-measures ANOVA with session as a factor; Session 1: $t_{(19)}=3.00, p=0.007$; Session 2: $t_{(19)}=1.92, p=$ 0.069; Session 3: $\left.t_{(19)}=2.98, p=0.008\right)$, suggesting little effect of learning on the VS response to the number of options for SELF. The vmPFC response to the choice equality was also unchanged over the session $\left(F_{(2,38)}=0.09, p=0.913\right)$.

Second, we examined whether the subjective value of the number of options for SELF depended on the variance in perceived probability of face-card appearance. The reason we assessed the variance in the perceived probability is as follows: In theory, if participants perceived that each option was associated with different reward probabilities, they might think that a larger number of available options would allow them to choose a "better" option, thereby increasing the probability of obtaining a reward. For instance, if participants perceived that the probabilities of face-card appearance were 30, 40, 50, and 60\% for the respective option positions, they might expect that the probability of obtaining a reward would increase with the number of options available (note that the theoretical increase in the probability of obtaining a reward with the number of options would be the same if the perceived probabilities of face-card appearance were, for example, $60,70,80$, and $90 \%$; i.e., variance rather than maximum or mean is the determinant factor). In contrast, if another participant perceived that the probabilities of face-card appearance were $90 \%$ for all four option positions, they would not expect that the probability of obtaining a reward would depend on the number of options available (because there were no better or worse options). To assess the possible effect of the variance in perceived option values on the subjective value of choice, we asked participants after the scan to indicate their perceived probability (percentage of all trials) of face-card appearance for each option position. We defined their answers as the perceived option values, and calculated the perceived option-value variance (the $\mathrm{SD}$ of the perceived option value among the four options). The VS response (neural $\beta_{\text {OP_SELF }}$ ) for the participants who reported no perceived option-value variance (i.e., the perceived option values were $50 \%$ for all four options; $n=10$ ) was significant $\left(t_{(9)}\right.$ $=2.51, p=0.034$ ) and not statistically different from that for the other participants $\left(t_{(18)}=-0.54, p=0.598\right.$; two-sample $t$ test $)$, suggesting that the VS response to the number of options for SELF was not due to the perceived variance in the option values. The perceived option-value variance (mean \pm SD across participants $=6.84 \pm 8.44)$ was not significantly correlated with the VS response (neural $\beta_{\text {OP_SELF }} ; r=0.26, p=0.272$ ) or with the subjective valuation of the number of options for SELF (subjective emotional pleasantness $\beta_{\text {OP_SELF }} ;=0.31, p=0.182$ ). Based on these results, we concluded that the perceived variance in the option values had little influence on the VS activation to the number of options for SELF. The perceived option-value variance was also not significantly correlated with the vmPFC response to the choice equality (neural $\beta_{\text {OP_EQUAL }} ; r=0.26, p=$ 0.266 ) or with the subjective valuation of the choice equality (subjective emotional pleasantness $\beta_{\mathrm{OP} \_\mathrm{EQUAL}} ; r=0.21, p=$ 0.376).

\section{Discussion}

The present study aimed to identify the neural substrate for subjective value of equality in choice opportunity. We set up an experimental situation in which participants compared their number of available options with those of another. By using this task procedure, we were able to probe specifically the value of social equality in the number of options without confounding by reward-outcome values or their equality. Our findings demonstrate that the vmPFC showed greater activation as the number of options between two players became equal. In contrast, the VS activation increased with the absolute number of options available to participants themselves and did not respond to the relative equality between the players. These results suggest that the vmPFC plays a critical role in subjective valuation of equality in choice opportunity.

Although the importance of equal opportunity and its distinction from equal outcome have long been emphasized in the fields of politics and economics (Arneson, 1989; Roemer, 2002; Breen, 2010), experimental research has never explored the neural basis of how humans subjectively value equal opportunity. We found that the vmPFC activation tracks the degree of equality in the numbers of options between two people. This vmPFC activation paralleled the result of self-reported emotional pleasantness, which also increased with the relative equality in the number of options. These findings suggest that the vmPFC, a region previously implicated in ethical judgment (Heekeren et al., 2003; Prehn et al., 2008), plays an important role in valuation of equality in choice opportunity. Moreover, the vmPFC reactivity to equality in the number of options varied across participants and was positively correlated with the subjective emotional pleasantness sensitivity. The vmPFC reactivity might therefore reflect individual differences in the extent to which a person values equality in choice opportunity. Thus, our subjectiverating and neuroimaging results provide the first empirical evidence that humans do value equality in choice opportunity and that the specific neural substrate involved in its valuation is the vmPFC.

In contrast to the vmPFC, activation in the VS did not reflect the option-number equality between the players. Instead, the VS activation increased with the number of options available to the participants themselves, but not their partners. Importantly, the VS activation was not explained by between-condition differences in the objective probabilities and risks of the reward outcome, because these factors were fixed regardless of the number of options. Our finding was consistent with recent fMRI studies that reported greater striatal activation to a stimulus indicating choice opportunity than to a stimulus indicating no choice, without regard to the expected outcome value of a choice (Leotti and Delgado, 2011; Fujiwara et al., 2013; Murayama et al., 2013). These findings provide the neural evidence for the value of choice opportunity, supporting the psychological literature describing the beneficial effects of choice opportunity on decision-making behaviors and subjective emotions (Suzuki, 2000; Tricomi et al., 2004; Patall et al., 2008; Leotti et al., 2010; Fischer and Boer, 2011). Of note, unlike the previous study (Leotti and Delgado, 2011), we explicitly instructed our participants that the number of options were irrelevant to the probability of obtaining a reward outcome. In addition, the VS activation was significant already in the initial session and unchanged over the experimental sessions, suggesting that the value associated with the number of options was little affected by learning from outcome feedback. Furthermore, the perceived variance in the probability of a reward outcome among the options was not related to the VS activation associated with the subjective value of the number of options. These results may further indicate that the value of choice represented in the VS is distinct of the value of reward outcomes.

The differential activation pattern we observed between the vmPFC and VS is notable. Specifically, the vmPFC activity reflected the degree of social equality (as indexed by similarity in option numbers) between the two players, whereas the VS re- 
flected participants' own number of options, regardless of how many the other player had. These findings are consistent with the idea that the vmPFC plays critical roles in processing social information, which has been supported by patient studies demonstrating that selective damages to the vmPFC cause the absence of emotions involving social comparison (Koenigs and Tranel, 2007; Shamay-Tsoory et al., 2007) and a reduction in inferred prosociality (Krajbich et al., 2009). Although fMRI studies have frequently reported coactivations of the vmPFC and VS, these two regions differentially contribute to value computation (Hare et al., 2008; Basten et al., 2010; Philiastides et al., 2010). Recent fMRI studies have begun to elucidate distinct roles of the vmPFC and VS in processing social values (Mobbs et al., 2009; Cooper et al., 2010; Zaki and Mitchell, 2011; Suzuki et al., 2012). For instance, Suzuki et al. (2012) examined the neural representation of reward values for self and others, and found that the vmPFC encoded reward prediction error for both self and others, whereas the VS encoded reward prediction error only for self, not for the other person. Zaki and Mitchell (2011) examined the brain activation in a social decision-making task, and reported that the activation to monetary outcomes in the vmPFC, but not in the VS, was modulated by social contexts. Together, the vmPFC seems to play a more important role than the VS in valuation of social information including equality in opportunity. Meanwhile, some other studies have reported that the vmPFC and VS show similar responses to social contexts (Tricomi et al., 2010; Bault et al., 2011; Kang et al., 2013). Future research will benefit from clarifying whether and how the vmPFC and VS are differentially involved in reward processing within a range of social contexts.

Several other patterns in our findings are also worth noting. First, the fact that vmPFC activity was not modulated by the choice opportunities of participants themselves is consistent with fMRI studies that have investigated the effect of choice opportunities on brain activation in nonsocial situations (Leotti and Delgado, 2011; Fujiwara et al., 2013). The vmPFC seems to be important for how self-determined choice influences subjective value of reward outcomes (Murayama et al., 2013), which should be distinguished from the value of choice in itself. Second, our behavioral results indicate that when the other player's choice opportunities increase, one's own emotional pleasantness decreases, although no corresponding effect is observed in activation of the VS or vmPFC. This apparent discrepancy between behavior and brain activation may be explained by differences between the postscan subjective rating task and the fMRI task: participants made active evaluations regarding the opportunity stimuli and spent as much time as they needed to do so in the postscan rating task, whereas they passively viewed the opportunity stimuli for only a few seconds in the fMRI task. In a situation like our fMRI task, individuals might focus primarily on features that are salient to them, and it may be that only those features affect subjective values. Our fMRI results imply that participants focused predominantly on their own choice opportunities and the choice equality between the players during the in-scanner task. This interpretation accords with previous studies showing that activation associated with subjective value in the reward system is dramatically influenced by what participants attend to (Hare et al., 2011; Lim et al., 2011). It is conceivable that the number of options available to others would also modulate reward system activity if participants were explicitly instructed to pay attention to it, which could be tested in future research. Third, we found that the sensitivity of subjective emotional pleasantness to the participants' own choice opportunities markedly varied across participants, and that the variation was greater than that for sensitivity to the other player's choice opportunities. Other studies have suggested that the value of one's own choice opportunities may change depending on various psychological factors such as depressed mood and susceptibility to illusion of control (Taylor and Brown, 1988; Leotti et al., 2010). Interestingly, these factors can have a greater influence on the value of one's own choice than on those of others (Golin et al., 1979), which may underlie our finding that interindividual variation in sensitivity of subjective emotional pleasantness to choice opportunity was larger when considering the participants' own number of options than those of the other players.

To conclude, our study demonstrates that the vmPFC, which has been implicated in reward-related information processing in a variety of situations, is also involved in valuation of social equality in choice opportunity. Although several animals seem to be sensitive to fairness and equality in reward outcomes (Brosnan, 2006; Range et al., 2009; Proctor et al., 2013), only humans care about equality in choice opportunity, a distinctive dimension of social equality that has been developed and enforced by modern social-cultural systems (Béteille, 1986, 1994; Buckholtz and Marois, 2012). The ability to value both equal opportunity and equal outcome and to take balance between them may be a hallmark of the ethical and moral sense that is uniquely human. Our findings may shed light on how a subjective value of equality in choice opportunity emerged in the human brain.

\section{References}

Arneson RJ (1989) Equality and equal opportunity for welfare. Philos Stud 56:77-93. CrossRef

Bartra O, McGuire JT, Kable JW (2013) The valuation system: a coordinatebased meta-analysis of BOLD fMRI experiments examining neural correlates of subjective value. Neuroimage 76:412-427. CrossRef Medline

Basten U, Biele G, Heekeren HR, Fiebach CJ (2010) How the brain integrates costs and benefits during decision making. Proc Natl Acad Sci U S A 107:21767-21772. CrossRef Medline

Bault N, Joffily M, Rustichini A, Coricelli G (2011) Medial prefrontal cortex and striatum mediate the influence of social comparison on the decision process. Proc Natl Acad Sci U S A 108:16044-16049. CrossRef Medline

Baumgartner T, Knoch D, Hotz P, Eisenegger C, Fehr E (2011) Dorsolateral and ventromedial prefrontal cortex orchestrate normative choice. Nat Neurosci 14:1468-1474. CrossRef Medline

Behrens TE, Hunt LT, Rushworth MF (2009) The computation of social behavior. Science 324:1160-1164. CrossRef Medline

Béteille A (1986) Individualism and equality. Curr Anthropol 27:121-134.

Béteille A (1994) Inequality and equality. In: Companion encyclopedia of anthropology (Ingold T, ed), pp 1010-1039. London: Routledge.

Breen R (2010) Social mobility and equality of opportunity: Geary lecture Spring 2010. Econ Soc Rev 41:413-428.

Brookfield S (2008) Radical questioning on the long walk to freedom: Nelson Mandela and the practice of critical reflection. Adult Educ Quart 58:95-109. CrossRef

Brosnan SF (2006) Nonhuman species' reaction to inequality and their implications for fairness. Soc Justice Res 19:153-185. CrossRef

Buckholtz JW, Marois R (2012) The roots of modern justice: cognitive and neural foundations of social norms and their enforcement. Nat Neurosci 15:655-661. CrossRef Medline

Clithero JA, Reeck C, Carter RM, Smith DV, Huettel SA (2011) Nucleus accumbens mediates relative motivation for rewards in the absence of choice. Front Hum Neurosci 5:87. CrossRef Medline

Cooper JC, Kreps TA, Wiebe T, Pirkl T, Knutson B (2010) When giving is good: ventromedial prefrontal cortex activation for others' intentions. Neuron 67:511-521. CrossRef Medline

Deichmann R, Gottfried JA, Hutton C, Turner R (2003) Optimized EPI for fMRI studies of the orbitofrontal cortex. Neuroimage 19:430-441. CrossRef Medline

Delhey J (2009) From materialist to postmaterialist happiness? National affluence and determinants of life satisfaction in cross-national perspective. WVR 2:30-54. 
Fischer R, Boer D (2011) What is more important for national well-being: money or autonomy? A meta-analysis of well-being, burnout, and anxiety across 63 societies. J Pers Soc Psychol 101:164-184. CrossRef Medline

FitzGerald TH, Friston KJ, Dolan RJ (2012) Action-specific value signals in reward-related regions of the human brain. J Neurosci 32:16417-16423. CrossRef Medline

Flemming TM, Rattermann MJ, Thompson RKR (2006) Differential individual access to and use of reaching tools in social groups of capuchin monkeys (Cebus apella) and human infants (Homo sapiens). Aquat Mamm 32:491-499. CrossRef

Fliessbach K, Weber B, Trautner P, Dohmen T, Sunde U, Elger CE, Falk A (2007) Social comparison affects reward-related brain activity in the human ventral striatum. Science 318:1305-1308. CrossRef Medline

Fujiwara J, Usui N, Park SQ, Williams T, Iijima T, Taira M, Tsutsui K, Tobler PN (2013) Value of freedom to choose encoded by the human brain. J Neurophysiol 110:1915-1929. CrossRef Medline

Golin S, Terrell F, Weitz J, Drost PL (1979) The illusion of control among depressed patients. J Abnorm Psychol 88:454-457. CrossRef Medline

Haber SN, Knutson B (2010) The reward circuit: linking primate anatomy and human imaging. Neuropsychopharmacology 35:4-26. CrossRef Medline

Hare TA, O'Doherty J, Camerer CF, Schultz W, Rangel A (2008) Dissociating the role of the orbitofrontal cortex and the striatum in the computation of goal values and prediction errors. J Neurosci 28:5623-5630. CrossRef Medline

Hare TA, Camerer CF, Knoepfle DT, Rangel A (2010) Value computations in ventral medial prefrontal cortex during charitable decision making incorporate input from regions involved in social cognition. J Neurosci 30:583-590. CrossRef Medline

Hare TA, Malmaud J, Rangel A (2011) Focusing attention on the health aspects of foods changes value signals in vmPFC and improves dietary choice. J Neurosci 31:11077-11087. CrossRef Medline

Heekeren HR, Wartenburger I, Schmidt H, Schwintowski HP, Villringer A (2003) An fMRI study of simple ethical decision-making. Neuroreport 14:1215-1219. CrossRef Medline

Inglehart R, Foa R, Peterson C, Welzel C (2008) Development, freedom, and rising happiness: a global perspective (1981-2007). Persp Psychol Sci 3:264-285. CrossRef

Izuma K, Matsumoto M, Murayama K, Samejima K, Sadato N, Matsumoto K (2010) Neural correlates of cognitive dissonance and choice-induced preference change. Proc Natl Acad Sci U S A 107:22014-22019. CrossRef Medline

Janowski V, Camerer C, Rangel A (2013) Empathic choice involves vmPFC value signals that are modulated by social processing implemented in IPL. Soc Cogn Affect Neurosci 8:201-208. CrossRef Medline

Kang P, Lee Y, Choi I, Kim H (2013) Neural evidence for individual and cultural variability in the social comparison effect. J Neurosci 33:1620016208. CrossRef Medline

Kennedy R (1989) Martin Luther King's constitution: a legal history of the Montgomery bus boycott. Yale Law J 98:295-321.

Knutson B, Adams CM, Fong GW, Hommer D (2001) Anticipation of increasing monetary reward selectively recruits nucleus accumbens. J Neurosci 21:RC159. Medline

Koenigs M, Tranel D (2007) Irrational economic decision-making after ventromedial prefrontal damage: evidence from the ultimatum game. J Neurosci 27:951-956. CrossRef Medline

Krajbich I, Adolphs R, Tranel D, Denburg NL, Camerer CF (2009) Economic games quantify diminished sense of guilt in patients with damage to the prefrontal cortex. J Neurosci 29:2188-2192. CrossRef Medline

Kranich L (1996) Equitable opportunities: an axiomatic approach. J Econ Theory 71:131-147. CrossRef

Kringelbach ML, Berridge KC (2009) Towards a functional neuroanatomy of pleasure and happiness. Trends Cogn Sci 13:479-487. CrossRef Medline

Kuhl BA, Shah AT, DuBrow S, Wagner AD (2010) Resistance to forgetting associated with hippocampus-mediated reactivation during new learning. Nat Neurosci 13:501-506. CrossRef Medline

Leotti LA, Delgado MR (2011) The inherent reward of choice. Psychol Sci 22:1310-1318. CrossRef Medline

Leotti LA, Iyengar SS, Ochsner KN (2010) Born to choose: the origins and value of the need for control. Trends Cogn Sci 14:457-463. CrossRef Medline
Lim SL, O’Doherty JP, Rangel A (2011) The decision value computations in the vmPFC and striatum use a relative value code that is guided by visual attention. J Neurosci 31:13214-13223. CrossRef Medline

Maldjian JA, Laurienti PJ, Kraft RA, Burdette JH (2003) An automated method for neuroanatomic and cytoarchitectonic atlas-based interrogation of fMRI data sets. Neuroimage 19:1233-1239. CrossRef Medline

Marshall G, Swift A, Routh D, Burgoyne C (1999) What is and what ought to be: popular beliefs about distributive justice in thirteen countries. Eur Sociol Rev 15:349-367. CrossRef

Mobbs D, Yu R, Meyer M, Passamonti L, Seymour B, Calder AJ, Schweizer S, Frith CD, Dalgleish T (2009) A key role for similarity in vicarious reward. Science 324:900. CrossRef Medline

Murayama K, Matsumoto M, Izuma K, Sugiura A, Ryan RM, Deci EL, Matsumoto K (2013) How self-determined choice facilitates performance: a key role of the ventromedial prefrontal cortex. Cereb Cortex, in press. CrossRef Medline

Patall EA, Cooper H, Robinson JC (2008) The effects of choice on intrinsic motivation and related outcomes: A meta-analysis of research findings. Psychol Bull 134:270-300. CrossRef Medline

Pattanaik PK, Xu YS (1990) On ranking opportunity sets in terms of freedom of choice. Rech Econ Louvain 56:383-390.

Philiastides MG, Biele G, Heekeren HR (2010) A mechanistic account of value computation in the human brain. Proc Natl Acad Sci U S A 107: 9430-9435. CrossRef Medline

Prehn K, Wartenburger I, Mériau K, Scheibe C, Goodenough OR, Villringer A, van der Meer E, Heekeren HR (2008) Individual differences in moral judgment competence influence neural correlates of socio-normative judgments. Soc Cogn Affect Neurosci 3:33-46. CrossRef Medline

Proctor D, Williamson RA, de Waal FB, Brosnan SF (2013) Chimpanzees play the ultimatum game. Proc Natl Acad Sci U S A 110:2070-2075. CrossRef Medline

Range F, Horn L, Viranyi Z, Huber L (2009) The absence of reward induces inequity aversion in dogs. Proc Natl Acad Sci U S A 106:340-345. CrossRef Medline

Roemer JE (2002) Equality of opportunity: a progress report. Soc Choice Welfare 19:455-471. CrossRef

Sanfey AG, Rilling JK, Aronson JA, Nystrom LE, Cohen JD (2003) The neural basis of economic decision-making in the ultimatum game. Science 300:1755-1758. CrossRef Medline

Shamay-Tsoory SG, Tibi-Elhanany Y, Aharon-Peretz J (2007) The greeneyed monster and malicious joy: the neuroanatomical bases of envy and gloating (schadenfreude). Brain 130:1663-1678. CrossRef Medline

Silverstein J (1996) The idea of freedom in burma and the political thought of Daw Aung San Suu Kyi. Pac Aff 69:211-228. CrossRef

Suzuki S (2000) Choice between single-response and multichoice tasks in humans. Psychol Rec 50:105-115.

Suzuki S, Harasawa N, Ueno K, Gardner JL, Ichinohe N, Haruno M, Cheng K, Nakahara H (2012) Learning to simulate others' decisions. Neuron 74: 1125-1137. CrossRef Medline

Tabibnia G, Satpute AB, Lieberman MD (2008) The sunny side of fairness: preference for fairness activates reward circuitry (and disregarding unfairness activates self-control circuitry). Psychol Sci 19:339-347. CrossRef Medline

Taylor SE, Brown JD (1988) Illusion and well-being: a social psychological perspective on mental health. Psychol Bull 103:193-210. CrossRef Medline

Tricomi EM, Delgado MR, Fiez JA (2004) Modulation of caudate activity by action contingency. Neuron 41:281-292. CrossRef Medline

Tricomi E, Rangel A, Camerer CF, O’Doherty JP (2010) Neural evidence for inequality-averse social preferences. Nature 463:1089-1091. CrossRef Medline

Tzourio-Mazoyer N, Landeau B, Papathanassiou D, Crivello F, Etard O, Delcroix N, Mazoyer B, Joliot M (2002) Automated anatomical labeling of activations in SPM using a macroscopic anatomical parcellation of the MNI MRI single-subject brain. Neuroimage 15:273-289. CrossRef Medline

Welzel C, Inglehart R (2010) Agency, values, and well-being: A human development model. Soc Indic Res 97:43-63. CrossRef Medline

Zaki J, Mitchell JP (2011) Equitable decision making is associated with neural markers of intrinsic value. Proc Natl Acad Sci U S A 108:19761-19766. CrossRef Medline

Zaki J, Schirmer J, Mitchell JP (2011) Social influence modulates the neura computation of value. Psychol Sci 22:894-900. CrossRef Medline 